\title{
The role of mass media in the formation of the ethnic identity of students in the context of the infodemia
}

\author{
Anastasia Grishina $^{1 *}$, Elena Dyakova $^{2}$, and Yanina Morozova ${ }^{1}$ \\ ${ }^{1}$ Don State Technical University, 344000, Rostov-on-Don, Russia \\ ${ }^{2}$ Rostov State Transport University, 344038, Rostov-on-Don, Russia
}

\begin{abstract}
The relevance of the study is due to the need for a deeper understanding of the factors that influence the formation of ethnic identity of modern youth. Most scientists agree that ethnic identity is formed mainly spontaneously, in the process of primary socialization of the individual, but this process is subject to the same spontaneous influences throughout the entire period of growing up. The mass media and the Internet space are the most powerful factors influencing modern people, including in the sphere of forming ideas about their ethnic group, its traditions and culture. The article presents the results of an empirical study conducted at the Don State Technical University, Rostov-on-Don, Russia, with a total sample of 100 people. Authors revealed significant differences in the psychological characteristics of students with different types of ethnic identity: hypo-identity, normal identity and hyper-identity. It was also revealed that the media is one of the factors in the formation of negative types of ethnic identity: students with hypoidenticity and hyperidenticity mainly receive information about other ethnic groups from media sources; students with normal identity receive such information in the family or from the close environment. Further research will be aimed at studying the information behavior of students with different types of ethnic identity, which will allow us to develop recommendations for preventing the spread of destructive forms of behavior on the Internet.
\end{abstract}

\section{Introduction}

To date, there are practically no people left who would not be exposed to one or another source of mass information, whether it be radio, television, the press or the Internet. Not always the information consumed by a person is positively colored, reliable and realistic. Often, the information flow is a well-thought-out strategy that shapes public opinion and social sentiment.

There are quite a large number of TV and radio programs and Internet resources aimed at forming a positive national identity among the citizens of the Russian Federation. The civil ideology chosen in this way for Russia as a multinational state should act in two directions: on the one hand, it is necessary to prevent conflicts on the basis of ethnic and

\footnotetext{
* Corresponding author: avgrishina.donstu@gmail.com
} 
religious affiliation, without contrasting one ethnic group with another, emphasizing the importance of each; on the other hand, it is important to preserve the connection of a person (a person, an individual) with their ethnic group, forming a "sense of security" and their own uniqueness. In this regard, the study of the processes of formation of ethnic identity and the factors influencing this process is extremely relevant at the present time.

We will briefly describe the main phenomena used in this article.

Ethnic identity is an integral part of a person's social identity, a psychological category that refers to the awareness of belonging to a particular ethnic community $[1,2,3]$. In its structure, there are usually three main components:

- cognitive-knowledge, ideas about the characteristics of one's own group and awareness of oneself as a member based on certain characteristics;

- affective-assessment of the qualities of one's own group, attitude to membership in it, the significance of this membership;

- behavioral-acceptance and assimilation of behavioral stereotypes characteristic of a particular ethnic group [4].

G. U. Soldatova considers ethnic identity as a continuum of types from hypo-identity to positive ethnic identity and to hyperidenticity [5]. The types of identity are identified on the basis of a wide range of the scale of ethnocentrism, starting from the "denial" of identity (hypo - identity), when negativism and intolerance towards one's own ethnic group are recorded, and ending with national fanaticism-the apotheosis of intolerance and the highest degree of negativism towards other ethnic groups (hyper-identity). A positive ethnic identity is a combination of a positive attitude towards one's own people with a positive attitude towards other peoples. It sets such an optimal balance of tolerance towards one's own and other ethnic groups, which allows us to consider it, on the one hand, as a condition for the independence and stable existence of an ethnic group, on the other - as a condition for peaceful intercultural interaction in a multi-ethnic world. [5]

Most scientists agree that ethnic identity is formed mainly spontaneously, in the process of primary socialization of the individual, at the same time, the awareness of belonging to a certain ethnic community becomes one of the first manifestations of the social nature of a person.

Identity is one of the most important mechanisms of personal development of social reality, which underlies the formation of a system of personal meanings. According to subjectively determined identifications, a person organizes and directs his behavior. Ethnic identity is a powerful factor in the formation and cohesion of ethnic groups and their social ties. Therefore, identification with a large social (ethnic) community can serve as a sufficiently strong catalyst for mass behavior and political action (especially in a crisis society). However, it should not be forgotten that there may also be an inverse relationship, since ethnic identity may be the result of politics and the influence of mass media (including Internet content), and not at all their source. [6, 7]

\section{Materials and methods}

Despite the existing work in this research area, we consider it necessary to conduct an additional study of the methods and methods of forming the ethnic identity of university students in the perception of media information.

Research hypotheses:

1. There may be differences in the psychological characteristics of students with different types of ethnic identity

2. It is likely that the media is one of the main factors in the formation of negative types of ethnic identity of university students.

The subject of the study is the ethnic identity of university students. 
The purpose of the study: to identify the influence of external factors on the level of formation of ethnic identity among university students.

The research base is Don State Technical University, Rostov-on-Don, Russia.

The empirical object of the study was the data of a survey of 100 students of the faculties:

Agro-industrial-46 people;

Psychology, pedagogy and defectology - 54 people.

The following research methods were used to test the proposed hypothesis and solve the tasks set:

1. Methods of collecting factual material:

a) theoretical analysis of the literature on the problem under study, including a conceptual analysis of previous studies;

2. Empirical methods:

b) "Types of ethnic identity" by G. U. Soldatova and S. V. Ryzhova;

c) Express questionnaire "Tolerance Index" by G. U. Soldatova, O. A. Kravtsova, O. E. Khukhlaev, L. A. Shaigerova;

d) Questionnaire of the formation of citizenship of the individual M. A. Boyko;

e) Value questionnaire Sh. Schwartz;

e) The scale of social distance (Bogardus scale, variant of L. G. Pochebut);

g) The author's questionnaire "The role of the media in the formation of ethnic and national identity in the student age»;

3. Methods of statistical processing of empirical data:

h) The results of diagnostic studies were subjected to statistical computer processing using the SPSS software.

Let's give a brief description of the respondents selected for the study:

The distribution of respondents by gender is shown in Figure 1.

$$
\text { - Boys = Girls }
$$

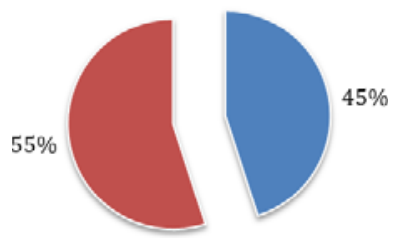

Fig. 1. Distribution of respondents by gender

The distribution of respondents by age is shown in Figure 2.

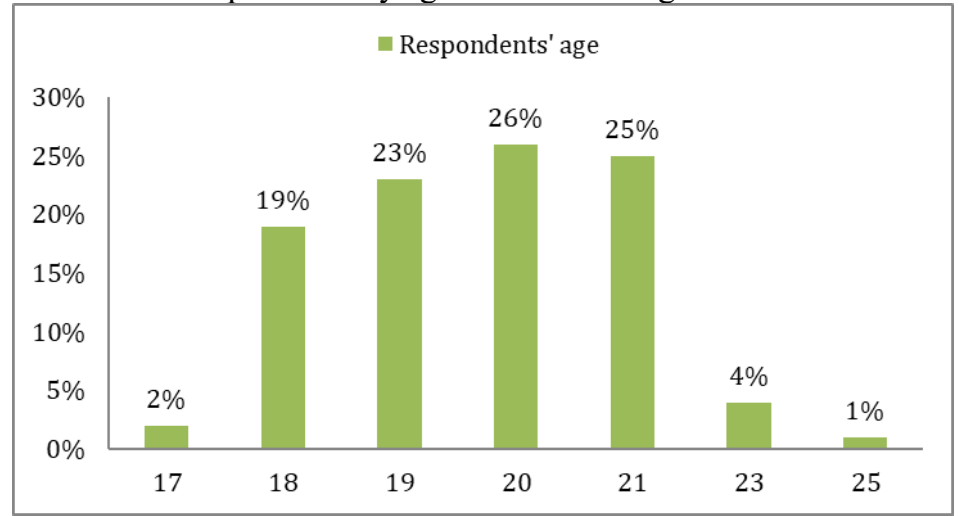

Fig. 2. Age distribution of respondents 
The ethnicity of the respondents is shown in Figure 3.

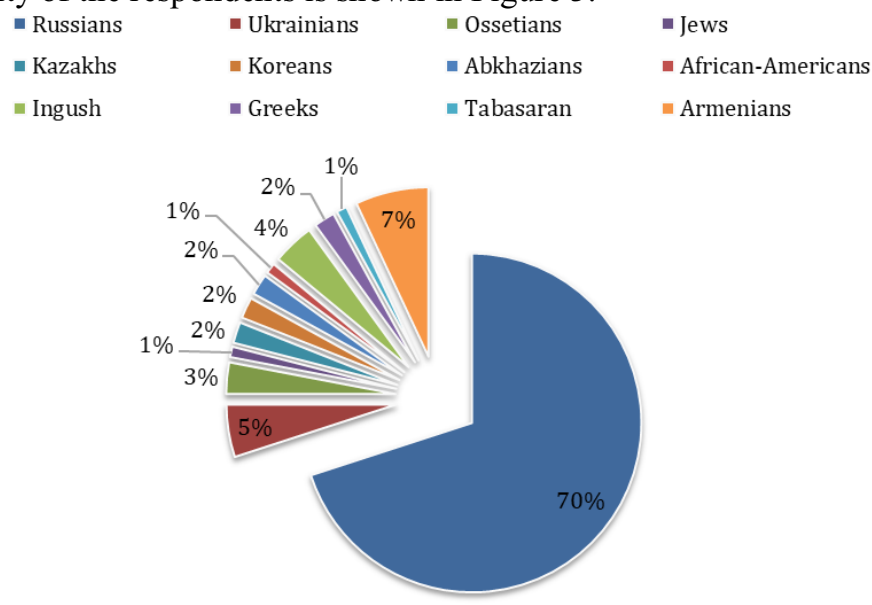

Fig. 3. Distribution of respondents by ethnicity

Thus, not only Russian students took part in the survey, but also representatives of numerous other nationalities living/studying at the Don State Technical University.

\section{Results}

The central methodology of this study was the method "Types of ethnic identity" by G. U. Soldatova and S. V. Ryzhova. Using this methodology, the respondents were divided into six types of ethnic identity. The data obtained are shown in Figure 4.

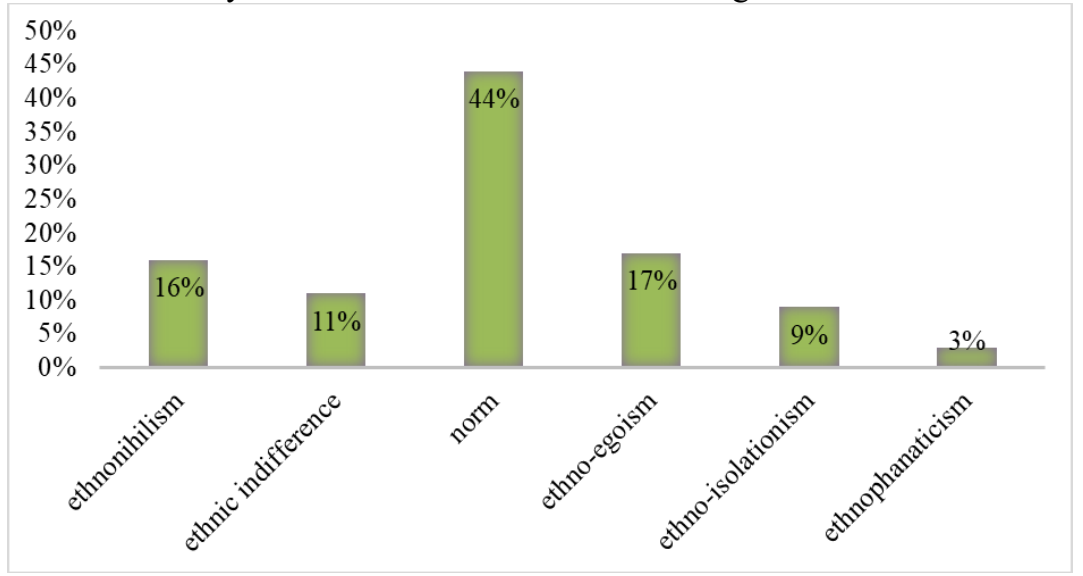

Fig. 4. Percentage distribution of respondents according to the method "Types of ethnic identity" by G. U. Soldatova and S. V. Ryzhova

According to these results, 44 respondents (44\%) out of 100 belong to the norm. Respondents who do not want to be involved in their own ethnic group were 16 people $(16 \%)$. Students with undetermined ethnicity -11 people $(11 \%) .17$ people $(17 \%)$ turned out to be ethno-egoists who express their irritation with other peoples and countries in a harmless verbal form. People who are convinced of their superiority and have a negative attitude towards other nations (xenophobia) - 9 people. And, ethnophanatics who are ready to go to any action in the name of ethnic interests -3 people $(3 \%)$. For a more correct 
study, taking into account the requirements of statistics, the respondents were divided into three large groups: norm (respondents with a normal level of identity), hyperidenticity (respondents with an increased level of identity) and hypoidenticity (respondents with a low level of identity) (Figure 5).

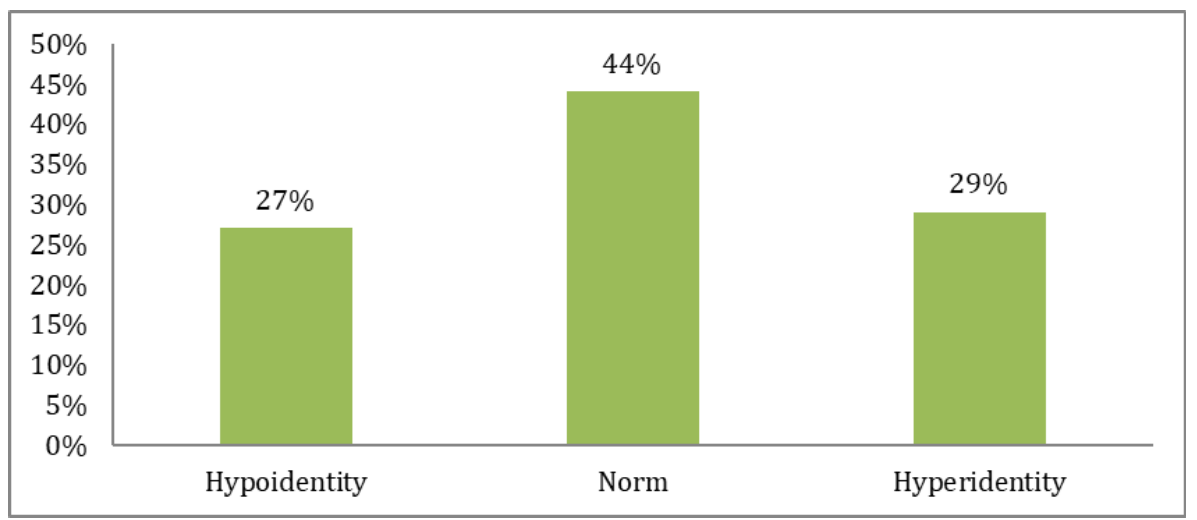

Fig. 5. Types of ethnic identity among the respondents of the study

Thus, it can be concluded that it is necessary to hold meetings (meetings/events) among students aimed at" smoothing out " interethnic and interethnic differences. The influence of the media on the distribution of students according to these types of ethnic identity will be described below.

Further research will be based on the distribution of respondents according to these three types of ethnic identity.

2. Consider the results of the rapid questionnaire "Tolerance Index" by G. U. Soldatova, O. A. Kravtsova, O. E. Khukhlaeva, L. A. Shaigerova.

Based on the data presented in Figure 6, the group with hypoidenticity and hyperidenticity - is dominated by a low tolerance index $(37 \%$ and $65.5 \%$ of respondents, respectively). In the group with a normal identity, a high tolerance index prevails $(54.5 \%$ of respondents). Also present in the sample of respondents are 5 people with an average tolerance index. These are ethno-egoists who are intolerant in verbal appeals, but in fact have nothing against other ethnic groups.

Respondents can be divided into three groups according to the tolerance index: low (37\% with hypoidenticity and 65.5\% with hyperidenticity), medium $(59.3 \%$ in the group with hypoidenticity, $45.5 \%$ in the group with norm and $34.5 \%$ in the group with hyperidenticity) and high (3.7\% of respondents with hypoidenticity, $54.5 \%$ in the group with norm and $0 \%$ in the group with hyperidenticity). 


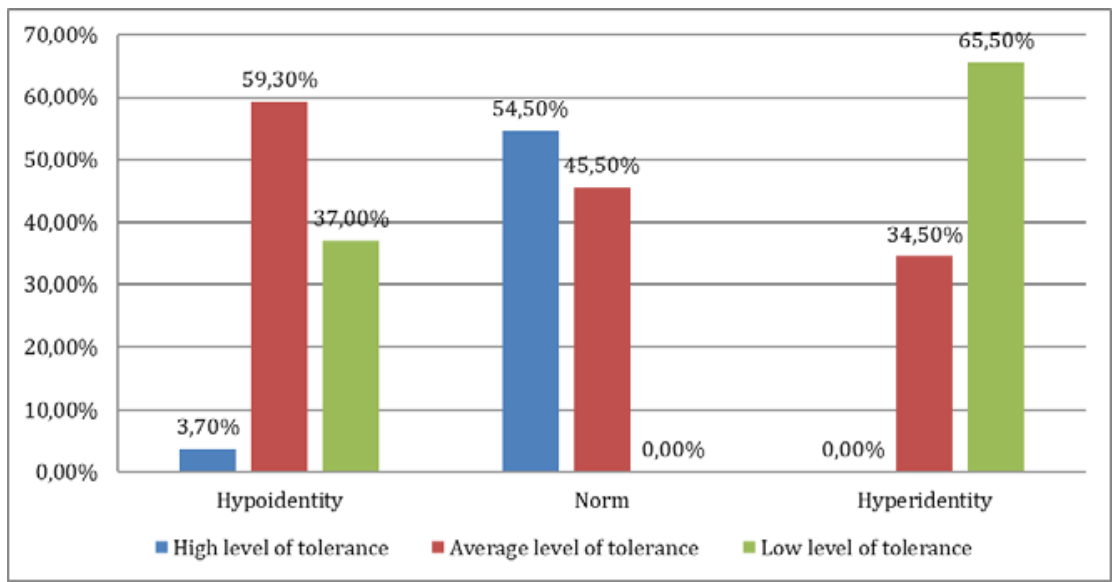

Fig. 6. Percentage distribution of respondents according to the rapid questionnaire "Tolerance Index" by G. U. Soldatova, O. A. Kravtsova, O. E. Khukhlaeva, L. A. Shaigerova.

3. According to the results of the "Questionnaire of the formation of citizenship of the individual" by M. A. Boyko, the following conclusions were made (Figure 7).

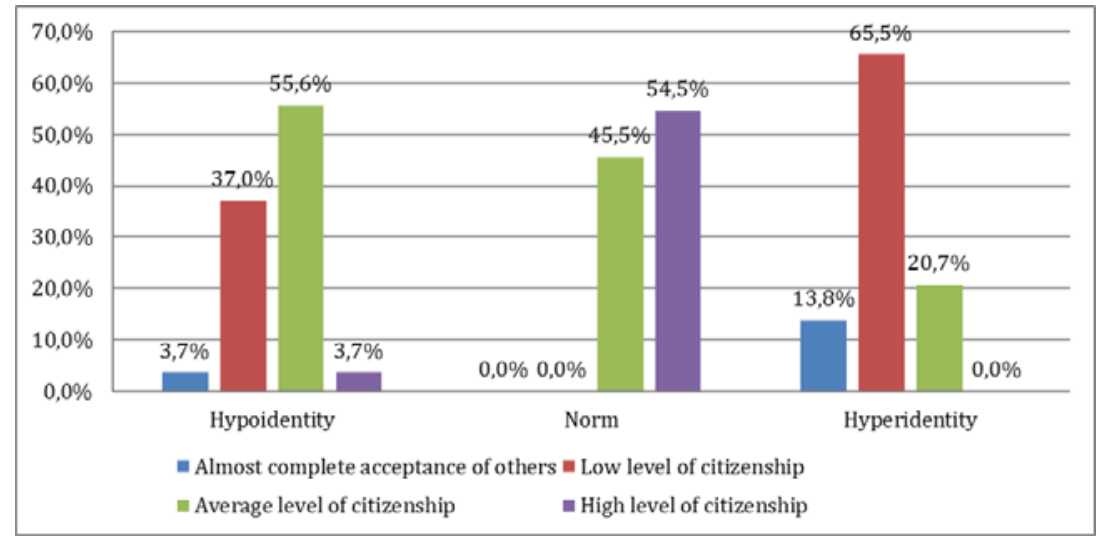

Fig.7. The percentage distribution of respondents in the" Questionnaire of the formation of citizenship of the individual " by M. A. Boyko

As with the previous methodology, the respondents were divided by tolerance levels. In the group with normal tolerance $-54.5 \%$ of respondents with highly developed citizenship. In the group with hypoidenticity and hyperidenticity-a low level of citizenship $(37 \%$ and $65.5 \%$ of respondents, respectively), as well as almost complete rejection of others-3.7\% in the group of respondents with hypoidenticity and $13.8 \%$ in the group of respondents with hyperidenticity. The average level of citizenship formation is present both in the group with normal identity $(45.5 \%)$ and in the groups with hypo-identity and hyper-identity $(55.6 \%$ and $20.7 \%$ of respondents, respectively).

The results of the three methods already carried out do not contradict each other, but only confirm the overall results.

The results of the study on the "Value Questionnaire" by Sh. Schwartz are presented in Figure 8. 


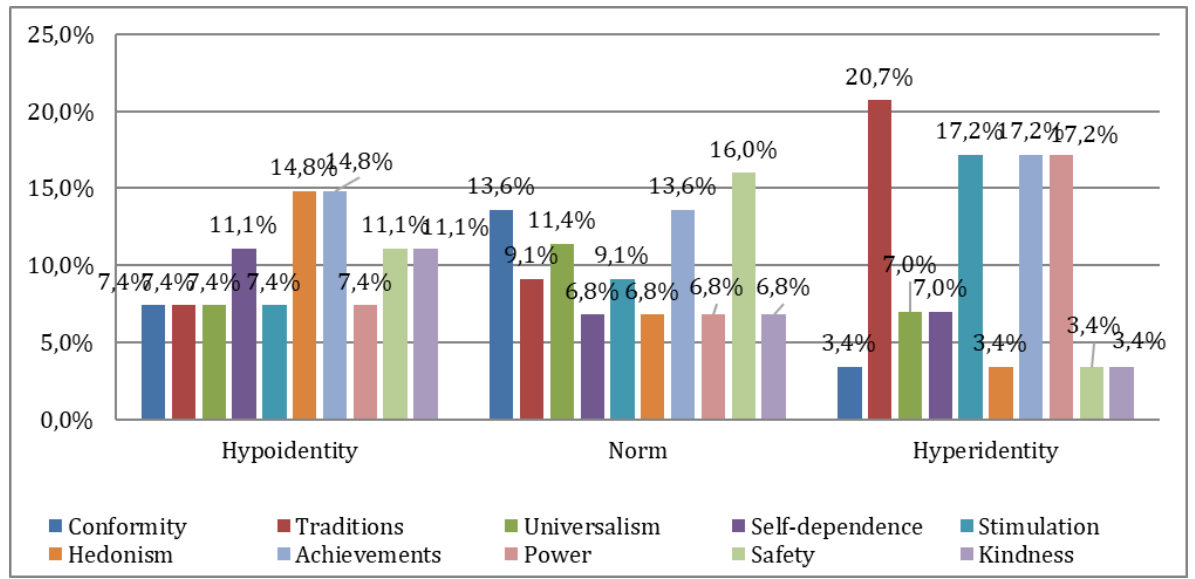

Fig. 8. Percentage ratio of value types among respondents

The personal and social values of the group of respondents with a normal identity include: security, achievement, conformity, universalism.

The personal and social values of the group of respondents with hypo-identity include: achievements, kindness, security, independence, hedonism.

The personal and social values of the group of respondents with hyperidenticity include: traditions, stimulation, achievements, and power.

It can be concluded that individual, personal values prevail over general social values in the hypo-identity group.

In a group with a normal identity, I have both personal and social values.

In a group with hyperidenticity, general social interests prevail over personal interests. But, at the same time, these general social interests are directed only at representatives of their ethnic group, nationality.

The percentage of respondents ' responses on the social distance scale (Bogardus scale, L. G. Pochebut variant) is shown in Figure 9.

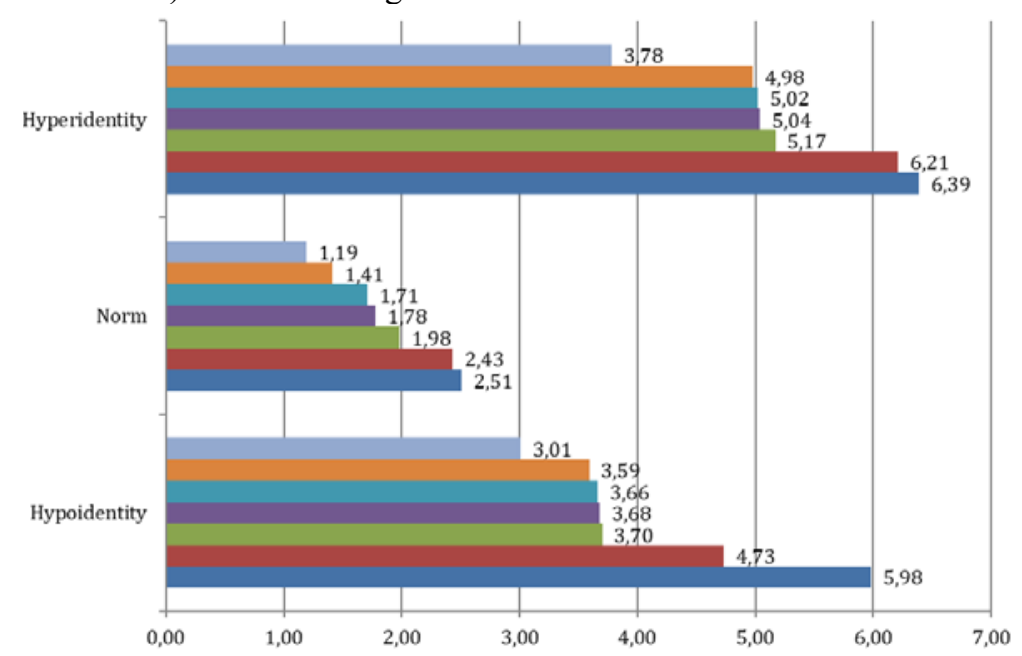

Fig. 9. Scale of gradation of respondents ' distance from representatives of other nationalities

In the group with a normal identity, respondents reacted positively to the fact that someone of another denomination or nationality would become a member of their families. 
They are not against interethnic and interethnic marriages. Also, many of them are friends with representatives of other religions and other ethnic groups.

A similar situation is present in the group with hypo-identity. But the motives in this group of respondents are slightly different. They would gladly prefer to be part of another ethnic group, to live in another country. Many are also thinking about changing their religion.

In the group with hyperidenticity, the results are exactly the opposite. These students do not recognize interethnic marriages, they would be against having a person of another ethnic group in their families. They prefer to live, work, and study among "their own".

6. The author's questionnaire "The role of the media in the formation of ethnic identity in the student age" was the final one among the methods used. It is through the author's questionnaire will identify the relationship of the media and the level of ethnic identity among students (Figure 10).

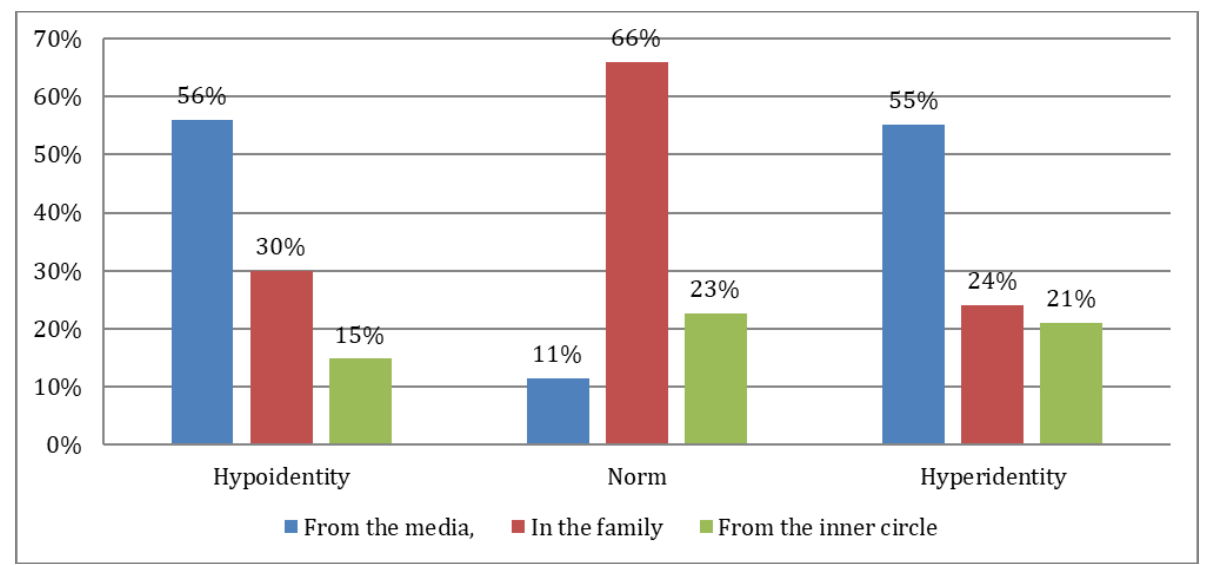

Fig. 10. Percentage distribution of respondents to answer the question: "Where do you get information about your and other ethnic groups?"

On the basis of statistical processing of the obtained results were revealed significant differences in the role of the media in the formation of ethnic identity among students with normal, Hyper - and hypodermically.

\section{Discussion}

The problem of ethnic identity has been a subject of researches in different contexts. L.Lara examined ethnic identities of immigrant and native adolescents who live in Spain, focusing on the ethnic labels they use, their development, and the relation with life satisfaction. Results show that ethnic identification was mainly determined by country of birth; however, in the case of immigrants, having immigrated at an early age favored the use of identity labels of the majority group. Immigrants were more likely to be in the achieved ethnic identity category than non-immigrants, although it was positively related to life satisfaction in both groups. [8]

J. Koutrelakos studied variability in ethnic identity among the ethnic groups that comprise the White racial category (Armenian, Greek, Jewish, European, Mixed White ancestry ("Irish and Italian"), and Pan-ethnic ("White")). Individuals who identified with Specific White groups (Armenian, Greek, Jewish) had higher ethnic identity scores than individuals who identified with Nonspecific White groups (European, Mixed, Pan-ethnic). Specific White groups also had more heritage education, ethnic language competency, and religious participation than Nonspecific White groups. [9] 
The study of Y. Long, F. Quan, Y. Zeng investigated the association between bicultural identity integration (BII, incorporating BII-harmony and BII-blendedness), national identity, and anxiety related to Coronavirus disease 2019 (COVID-19) among ethnic minority college students. The authors concluded that national identity could have the function of protecting ethnic minority college students from COVID-19-related anxiety. Emphasizing individualistic personal power values could increase COVID-19-related anxiety, whereas a collectivist identity reduces anxiety. [10]

R. S. Weisskirch, et al, studied ethnic identity among Jewish Americans and white Americans: Jewish Americans rated themselves as significantly higher on measures of ethnic and U.S. identity compared with White Americans but not as highly as ethnic minorities. Ethnic identity search, affirmation, and resolution also predicted higher selfesteem for Jewish Americans, similar to the pattern for other ethnic groups. In addition, ethnic identity search and affirmation moderated the link between perceived discrimination and depressive symptoms among Jewish Americans. [11]

Research of S. El Bouhaddani, L. Van Domburgh, B. Schaefer, et al, shows that the prevalence of psychiatric problems is higher in ethnic minority youth compared to native youth. The results underline the protective effect of ethnic identity against mental health problems. [12]

S. Fisher, L.A. Wheeler, P.G. Arora examined the moderating effect of social support on the relationship between ethnic identity and substance use in a sample of multiracial adolescent youth. Analyses indicated that ethnic affirmation was negatively related to frequency of, but not quantity of substance use. Teacher support was negatively related to both frequency and quantity of substance use, while parent support was only related to frequency. Further, teacher and parent support emerged as moderators of ethnic affirmation and frequency and quantity of substance use respectively. [13]

The study of P. Jugert, L. Leszczensky, S. Pink investigated the effects of ethnic minority adolescents' ethnic self-identification (host country, dual, or heritage country) on friendship choices among ethnic majority and minority peers. Results showed that ethnic minority adolescents' ethnic self-identification affected friendship selection beyond ethnic homophily. While host country and dual identification was beneficial with respect to friendships with both ethnic majority and minority peers, heritage country identification was detrimental to relations with both of them. [14]

X. Zhou, R. M. Lee, M. Syed examined ethnic identity developmental trajectories during the transition to college in longitudinal study and found parental ethnic socialization (as a factor of ethnic identity formation) to have a continued influence on ethnic identity development in college. [15]

Our research complements the outlined studies of ethnic identity and the factors of its formation, considering this process in the context of the influence of the media.

\section{Conclusion}

Significant differences in the psychological characteristics of students with different types of ethnic identity were identified, allowing us to describe the psychological profiles of the corresponding types:

1. The type of ethnic identity "Norm". This type includes $44 \%$ of respondents, who can be described as follows: "A high level of tolerance, respect for both their nation, ethnic group, people, religion, and representatives of other peoples, nationalities, and religions. This group of respondents identifies such values as kindness, achievement, and conformity. They are open to others. Many of them would be able to marry a representative of another nationality, or are ready to see a person of another nationality or religion as a family member. According to the author's questionnaire, these respondents prefer television to 
other media, they are more loyal to what is broadcast on television, they often watch news TV shows or programs that discuss acute social topics. It can be assumed that the media are probably one of the factors that influence the formation of national identity among the students of the studied sample of respondents. "

2. The type of ethnic identity "Hypo-identity". Some of the respondents do not want to be involved in their own ethnic group, or whose own nationality causes a degree of extreme irritation, can be characterized using the methods carried out as follows: "People who are inclined to deny their ethnicity, who want to leave their country in the near future, go abroad. Low level of tolerance for their nation. The personal and social values of this group include: security, achievements, hedonism. These respondents would like to see representatives of other nationalities among their neighbors, colleagues, and friends. They prefer the Internet to other mass media. They are more loyal to the news of foreign publications. They are not interested in regional and federal news. They recognize that Russia is a multinational country, but they do not take any part in any activities aimed at forming the national identity of their fellow citizens."

Another part of the respondents from this group is more indifferent to any federal or national news. She is more interested in her own development and getting her own benefits for her life. Achievement, power, and hedonism are the preferred types of value. Their national identity is characterized by a blurred, superficial view of this phenomenon. They prefer the Internet to television. They are ready to see representatives of other nationalities among their friends, colleagues, relatives and neighbors."

3. Type of ethnic identity "Hyperidenticity". This group of respondents also has only a superficial idea of their national identity. But at the same time, they can speak unflatteringly about representatives of other nationalities. Basically, this is a harmless, verbal form, expressed in the use of "nicknames", nicknames, anecdotes, which emphasize their uniqueness and privilege as representatives of their nationality. They are ready to be friends with representatives of other nationalities, but they would be extremely undesirable if they became members of their families. They mostly watch federal and regional TV programs dedicated to international events.

Some of the respondents from the group with hyperidenticity - "xenophobes", it is highly undesirable, even negative, to have someone from a different nationality or religion become a member of their families. They prefer regional TV shows. Their values: tradition, stimulation, power. Despite the fact that they live in Russia, they have an extremely negative attitude to Orthodoxy, their families would be categorically against interethnic marriages. They also prefer to live in communities and see "their own" among their neighbors. They tend to consider their nation, nationality, and religion superior to others.

Thus, it can be assumed that respondents who prefer television to other mass media are more susceptible to the formation of national identity in line with state policy aimed at recognizing Russia as a multinational and multi-religious country.

Respondents who prefer to a greater extent Internet resources, Internet news, either deny the existence of ethnic identity at all (are indifferent to it), or, on the contrary, are inclined to a rigid division of people by ethnicity and religion.

\section{Limitations}

Our research has some limitations. We didn't study the correlation between the age and gender characteristics of the respondents and their ethnic identity, but obviously, type of ethnic identity and the level of its formation among representatives of different age and gender may vary due to different reasons. 


\section{References}

1. O.A. Andrienko, T.A. Bezenkova, Azimuth of Scientific Research: Pedagogy and Psychology 9(4) (33), 304-306 (2020) doi.org/10.26140/anip-2020-0904-0069

2. M.M. Mishina, G.M. Mursalyeva, Bulletin of the Moscow State Regional University Psychological sciences. 1, 84-94 (2018) doi.org/0.18384/2310-7235-2018-1-84-93

3. I.V. Abakumova, V.F. Boguslavskaya, A.V. Grishina, Psychology in Russia 9, 112 120 (2016) doi.org/10.11621/pir.2016.0108

4. V.V. Gritsenko, L.V. Ostapenko, I.A. Subbotina, Sotsial'naya psikhologiya i obshchestvo = Social Psychology and Society 11(4), 165-181 (2020) doi.org/10.17759/sps.2020110412

5. G.U. Soldatova, S.V. Chigarkova, E.V. Kulesh, M.Yu. Tikhomirov, Psikhologicheskie Issledovaniya 11, 62, 8 (2018). http://psystudy.ru/index.php/eng/2018v11n62e/1662soldatova62.html

6. V.A. Achkasov, Bulletin of St. Petersburg State University 6(1), 85-91 (2012) https:/cyberleninka.ru/article/n/etnicheskaya-i-natsionalnaya-identichnosti-vsovremennom-mire. (accessed: 10. 03. 2021).

7. V.K. Malkova, Kommunikologiya 5(3), 101-117 (2014) http://psystudy.ru/index.php/num/2018v11n62/1650-soldatova62.html (accessed: 10. 03. 2021).

8. L. Lara, Psicol. Refl. Crít. 31, 19 (2018) doi.org/10.1186/s41155-018-0100-5

9. J. Koutrelakos, Psychological reports 112(3), 745-762 (2013) doi.org/10.2466/17.10.PR0.112.3.745-762

10. Y. Long, F. Quan, Y. Zheng, Psychol Res Behav Manag. 14, 239-249 (2021) doi.org/10.2147/PRBM.S294547

11. R.S. Weisskirch, S.Y. Kim, S.J. Schwartz, S.K. Whitbourne, Identity 16(3), 127141(2016) doi.org/10.1080/15283488.2016.1190724

12. El Bouhaddani S., L. Van Domburgh, B. Schaefer, et al., Soc Psychiatry Psychiatr Epidemiol 54, 343-353 (2019) doi.org/10.1007/s00127-019-01658-1

13. S. Fisher, L.A. Wheeler, P.G. Arora, J. Chaudry, J. Barnes-Najor, Substance use \& misuse 54(9), 1417-1428 (2019) doi.org/10.1080/10826084.2019.1573834

14. P. Jugert, L. Leszczensky, S. Pink, Journal of research on adolescence, The official journal of the Society for Research on Adolescence 28(2), 379-395 (2018) doi.org/10.1111/jora.12337

15. X. Zhou, R.M. Lee, M. Syed, Developmental Psychology 55(1), 157-169 (2019) doi.org/10.1037/dev0000634 